\title{
Evaluation of Tuberculosis Vaccine Candidate, pcDNA3.1-rpfD using Mycobacterial Growth Inhibition Assay (MGIA)
}

\author{
Mifa Nurfadilah ${ }^{1}$, Andriansjah Rukmana ${ }^{2 *}$, Fithriyah Sjatha $^{2}$ \\ ${ }^{1}$ Master Programme in Biomedical Science, Faculty of Medicine, Universitas Indonesia, Jakarta, Indonesia \\ ${ }^{2}$ Departement of Microbiology, Faculty of Medicine, Universitas Indonesia, Jakarta, Indonesia
}

ARTICLE INFO

Article history:

Received July 19, 2021

Received in revised form August 25, 2021

Accepted September 23, 2021

KEYWORDS:

BACTEC ${ }^{\mathrm{TM}}$ MGIT $^{\mathrm{TM}}$,

IFN $\gamma$,

MGIA,

RpfD,

Time to positivity

\begin{abstract}
Resuscitation-promoting factor $D(R p f D)$ is a protein involved in the resuscitation of dormant bacteria. A new tuberculosis vaccine carrying the $r p f D$ gene has been successfully constructed, pcDNA3.1-rpfD. It was demonstrated that this vaccine exhibits cellular and humoral immune responses. Therefore, within this study, the efficacy of this new vaccine candidate was evaluated using mycobacterial growth inhibition assay (MGIA). MGIA is a functional assay that measures the complex host immune response, peripheral blood mononuclear cell (PBMC) and splenocyte from BALB/c mice against mycobacteria. With BACTEC ${ }^{\mathrm{TM}}$ MGIT $^{\mathrm{TM}}$ 960 automated system, the effect of vaccination on bacterial growth was reported as a time to positivity (TTP) in hours. The mean of TTP from the vaccinated group (both pcDNA3.1-rpfD and BCG) was higher than the negative control group. These results suggest that pcDNA3.1-rpfD may be effective in controlling tuberculosis growth and may provide a clue for the development of the tuberculosis vaccine. In addition, despite previous evidence that IFN $\gamma$ was essential for tuberculosis immunity, IFN $\gamma$ (interferon gamma) production was found not to be correlated with mycobacterial inhibition. Therefore, these findings offer an alternative method to evaluate vaccine candidates than the assessment using IFN $\gamma$ only.
\end{abstract}

\section{Introduction}

Tuberculosis (TB) is a burden for the world, reaching 10 million new cases and 1.2 million deaths per year, driving the deadliest contagious disease (WHO 2020). The only clinically approved vaccine against TB is Bacille Calmette-Guérin (BCG). It gives reliable protection against severe TB in children, but its efficacy is extremely variable in adults (Fine 1995). This limitation urges the need for a new TB vaccine to control the spread of the infection. Although there are many TB vaccines in the pipeline, their trial phase is still overshadowed by unpromising results. Therefore, continuous efforts are carried out for developing TB vaccines including methods to validate correlates of protection in early screening.

In 2017, a new tuberculosis DNA vaccine, pcDNA3.1-rpfD has been successfully constructed (Rakhmawati 2017). It is composed of the pcDNA3.1 vector and the resuscitation-promoting factor $\mathrm{D}$

* Corresponding Author

E-mail Address: andriansjah.ms@ui.ac.id
( $r p f D)$ gene. The pcDNA3.1 vector was designed to allow replication in bacterial cells and expression of the cloned gene in mammalian cells (Invitrogen 2010). The cloned gene, rpfD encodes a protein that plays a role in the resuscitation of Mycobacterium tuberculosis (Mukamolova et al. 2002). Rakhmawati 2017 demonstrated that pcDNA3.1-rpfD induced cellular immune responses characterized by the production of IL-12 and IFN $\gamma$, important cytokines in controlling tuberculosis infection. Humoral immune response was also successfully induced which was defined by the production of IgG anti-RpfD antibodies in BALB/C mice, suggesting that it may serve as a potent vaccine candidate. Moreover, Pratama 2019 evinced that the strongest induced IgG subclass was IgG2a which bears an important role in facilitating M. tuberculosis eradication by complement (Macedo et al. 2011) or antibody-dependent cell-mediated cytotoxicity (ADCC) (Kips et al. 1985).

Following the successful completion of in vitro study, TB vaccine candidates must enter the extensive in vivo study to establish safety, efficacy, and potency. Mouse models can be used to aid in the identification 
of correlates protection through challenge studies (Ordway and Orme 2001). Nevertheless, not all laboratories support this risky-challenge assay, and more so as TB disease progresses, animals may experience TB symptoms, pain and will eventually die of pulmonary insufficiency. In the effort of overcoming this problem, mycobacterial growth inhibition assay (MGIA) has been used as an assay for down-selecting TB vaccine or 'gating' before in vivo assay (Tanner 2015). Therefore, only the strong candidate is permitted for in vivo challenge and thus fulfilling the "protection" in the animal model principle. Besides, MGIA has been established to produce output that was relevant to the results of the challenge assay. Yang et al. 2016 proved that there was a significant correlation between the inhibitory effect based on the MGIA and the challenge assay, supporting the MGIA as an alternative method for the challenge assay. In this study, BACTEC MGITbased MGIA was adapted for assessment of vaccine candidate, pcDNA3.1-rpfD efficacy by measuring mycobacterial survival after incubation with PBMCs or splenocytes from BALB/c mice.

\section{Materials and Methods}

\subsection{Isolation and Confirmation of Recombinant pcDNA3.1-rpfD Plasmid}

Recombinant pcDNA3.1-rpfD and pcDNA3.1 plasmid control were isolated from Escherichia coli DH5 $\alpha$ using Hispeed Plasmid Midi Kit (QIAGEN) following manufacturer instruction. The presence of the $r p f D$ gene in the isolated plasmid was confirmed using conventional PCR with primer $\mathrm{F}_{-} r p f D$ and $\mathrm{R}_{-}$ rpfD, or using primer set $F_{-}$cmV/R_rpfD for correct direction of inserted gene (Rakhmawati 2017).

\subsection{Mice Immunization}

Eighteen BALB/c mice within aged of $6-8$ weeks were divided into 3 groups of experiment. Mice were immunized intramuscularly with $100 \mu \mathrm{g} / 100$ ul pcDNA3.1-rpfD as treatment group, pcDNA3.1 as negative control group or with $100 \mathrm{ul}$ (equal to 2-8 x $10^{5} \mathrm{CFU}$ ) of BCG SII vaccine intraperitoneally (Rakhmawati 2017). All immunization was carried out three times within two weeks interval. One week after last immunization, mice were terminated followed by blood collection and sera separation, PBMC and splenocytes isolation. Ethical approval for this study was obtained from Komite Etik Penelitian Kesehatan FKUI-RSCM, number 616/UN2.F1/ETIK/ PPM.00.02/2020.

\subsection{Sera, PBMC and Splenocytes Isolation}

Blood from terminated mice were collected via cardiac puncture, followed by centrifugation for sera separation and PBMC isolation using densitygradient centrifugation with Histopaque ${ }^{\circledR}$ (Sigma) (Riedhammer et al. 2014). Mice splenocytes were isolated from fresh spleen aseptically. Both PBMC and splenocytes were adjusted to $3 \times 10^{6}$ cells in total 300 ul of RPMI 1640 (Gibco), 2 mM L-glutamine with additional $25 \mathrm{mM}$ HEPES for PBMC or $10 \%$ of FBS (Sigma) for splenocytes.

\subsection{In Vitro Mycobacterial Growth Inhibition Assay}

The following method was adopted from Zelmer $e t$ al.2016 and Tanner et al. 2019 with slight modification. Prepared splenocytes and PBMC were co-cultured with 0.0005 McFarland of Mycobacterium tuberculosis H37Rv strain, followed by incubation $37^{\circ} \mathrm{C}$ with $5 \%$ $\mathrm{CO}_{2}$ for 96 hours. For PBMC group, 10\% of autologous sera was added to the co-culture. After incubation, co-culture were centrifuged followed by $300 \mu \mathrm{l}$ isolation of supernatant for cytokine analysis and obtained pellet were inoculated in to MGIT tube (BD Biosciences) and incubated until they were positively detected.

\subsection{IFN $\gamma$ Measurement}

IFN $\gamma$ concentration in co-cultured supernatants were measured using mouse IFN gamma ELISA kit (Invitrogen) according to the manufacturer's instructions. Briefly, the assay was performed with incubating $100 \mu$ undiluted supernatant into pre-coated wells followed by incubation at room temperature(RT) for $1 \mathrm{~h}$. After incubation and washing step, biotin conjugate and streptavidin-HRP were added subsequently followed also by $1 \mathrm{~h}$ incubation at RT for each reagent and vigorous washing steps. Finally, stabilized chromogen substrate was added followed by 30 minutes incubation at RT. Reaction was stopped by adding stop solution followed by absorbance measurement using ELISA reader Elx800 BioTek at $450 \mathrm{~nm}$ and cytokine concentration was calculated in comparison to standard IFN $\gamma$ concentration curve. 


\subsection{Statistical Analysis}

Statistical Package for the Social Sciences (SPSS) was used to perform statistical analysis with p-value $>0.05$.

\section{Results}

\subsection{Isolation and Confirmation of Recombinant pcDNA3.1-rpfD Plasmid}

Electrophoresis result showed that the isolated plasmids were at the length of around 5,428 bp and $5,893 \mathrm{bp}$, corresponds to the size of pcDNA3.1 and pcDNA3.1-rpfD, respectively (Figure 1a). Furthermore,

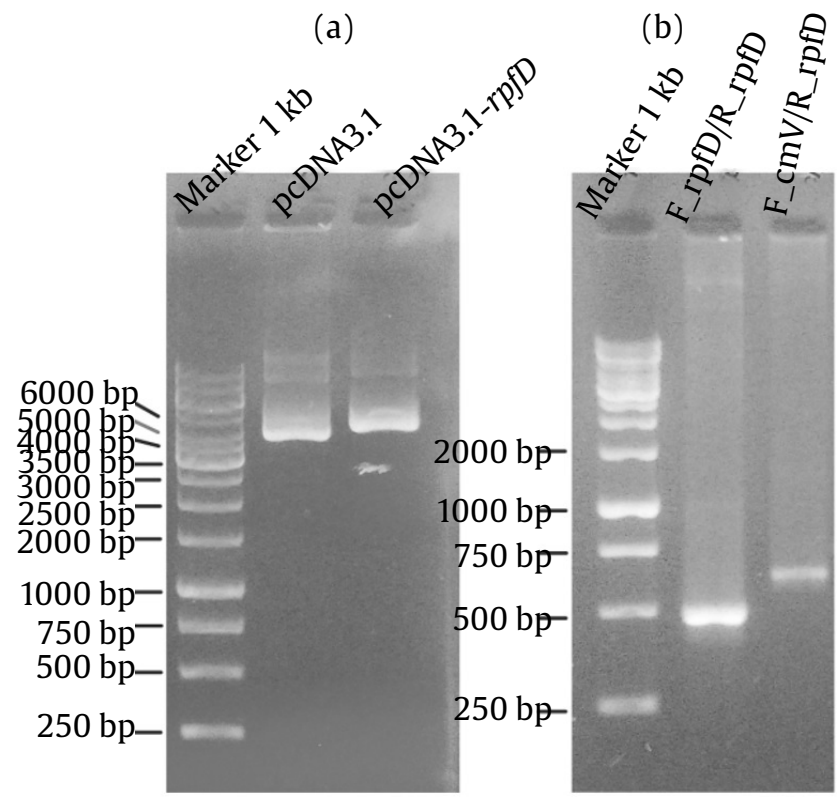

Figure 1. Electrophoresis result of (a) pcDNA3.1 and pcDNA3.1-rpfD plasmid (b) PCR product using primer sets of F_rpfD/R_rpfD and F_cmV/R_rpfD

(a)

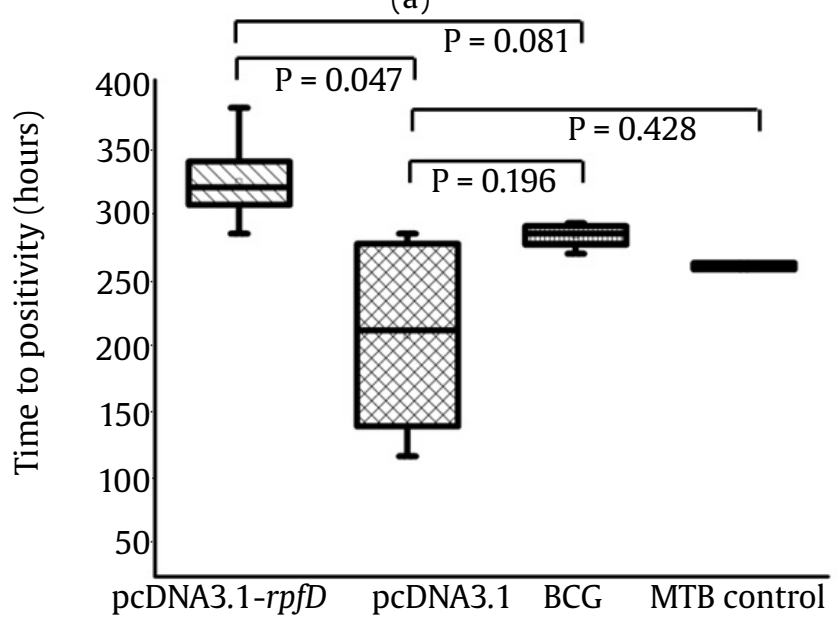

Treatment group the PCR product showed a band around $465 \mathrm{bp}$, indicating the $r p f D$ gene was successfully amplified. Besides, the PCR product showed that the direction of the $r p f D$ gene insertion was correct, as evidenced by the presence of a band around $673 \mathrm{bp}$ (Figure 1b).

\subsection{Evaluation of SeedVaccine Protection Based on Time to Positivity}

Immune cells (PBMCs or splenocytes) were cocultured with $M$. tuberculosis for 96 hours to give immune cells time for delivering their responses. The effect was expected since the incubation condition was set to $37^{\circ} \mathrm{C}$ and $5 \% \mathrm{CO}_{2}$, which favors the growth of mammalian cells. Using the BACTEC ${ }^{\mathrm{TM}}$ MGIT $^{\text {TM }}$ system, mycobacterial growth in each tube was determined by TTP in hours. The higher TTP was observed in the test and positive control groups compared to the negative control group, as depicted in Figure 2.

Regarding splenocyte co-culture, the mean of TTP from the test group (pcDNA3.1-rpfD), negative control group (pcDNA3.1), and positive control group (BCG) was $323( \pm 31), 200( \pm 77)$, and $283( \pm 8)$ hours, respectively. The mean of TTP from the test group was higher than the negative control group ( $p=0.047$ ). Likewise, the TTP of the positive control group compared to the negative control group $(\mathrm{p}=$ $0.196)$. As for the test group, it has a higher mean than the positive control group ( $p=0.081$ ). There was no significant difference in TTP from the pcDNA3.1 group and $M$. tuberculosis control. As a control, $M$. tuberculosis was incubated in RPMI-S media without splenocytes, indicating that the inhibitory effect was derived from splenocytes.

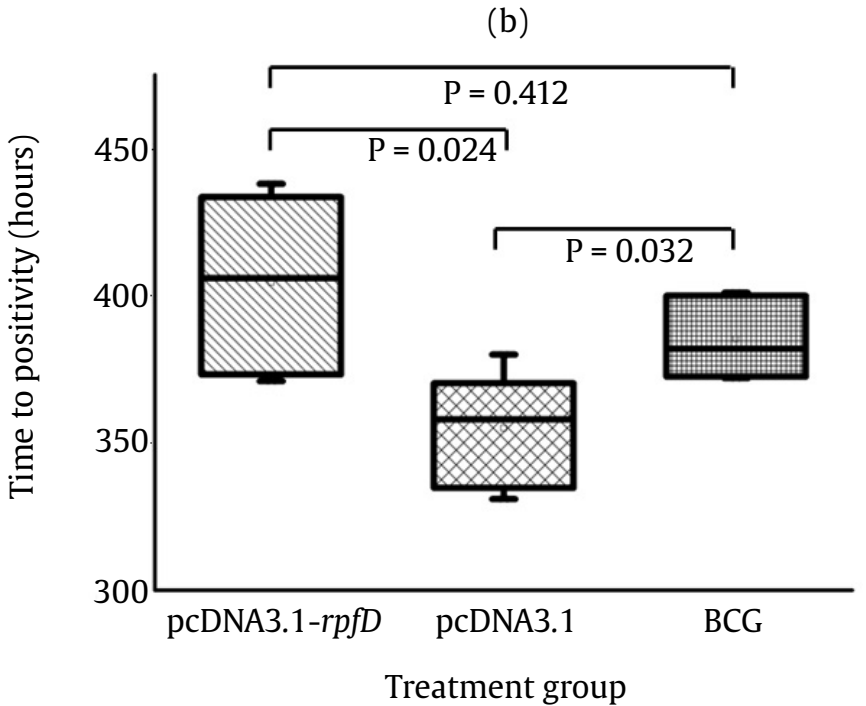

Figure 2. Comparison of MGIA responses expressed in TTP between study groups. (a) TTP of M. tuberculosis co-cultured with splenocyte, (b) TTP of M. tuberculosis co-cultured with PBMC 
A similar trend was observed in the TTP of PBMC co-culture. The mean of TTP from the test group (pcDNA3.1-rpfD), negative control group (pcDNA3.1), and the positive control group (BCG) was $404( \pm 31)$, $355( \pm 19)$, and $385( \pm 14)$ hours, respectively. The mean of TTP from the test group was higher than the negative control group ( $\mathrm{p}=0.024)$. Likewise, the mean TTP of the positive control group compared to the negative control group ( $\mathrm{p}=0.032$ ). Meanwhile, the test group has a higher mean than the positive control group $(\mathrm{p}=0.412)$.

\subsection{Analysis of IFN $\gamma$ Levels Based on ELISA}

To understand the immune response after vaccination, we measured the cytokine associated with
TB infection, IFN $\gamma$. The mean of IFN $\gamma$ concentration from splenocyte- $M$. tuberculosis co-culture (after subtraction of the absorbance from the nil control) was not significant between the test group, negative control, and positive control group ( $\mathrm{p}=0.387$ ). Likewise, there was no significant difference between these treatment groups and the splenocyte control group (Figure 3 ). The splenocyte control group was splenocytes from each treatment group incubated without $M$. tuberculosis.

IFN $\gamma$ was also detected in the supernatant of $\mathrm{PBMC}+$ M. tuberculosis co-culture. However, no significant differences were observed in pcDNA3.1-rpfD, pcDNA3.1, and BCG groups. PBMC control group, when compared with these treatment groups, also has no significant difference in IFN $\gamma$ levels (Figure 4).

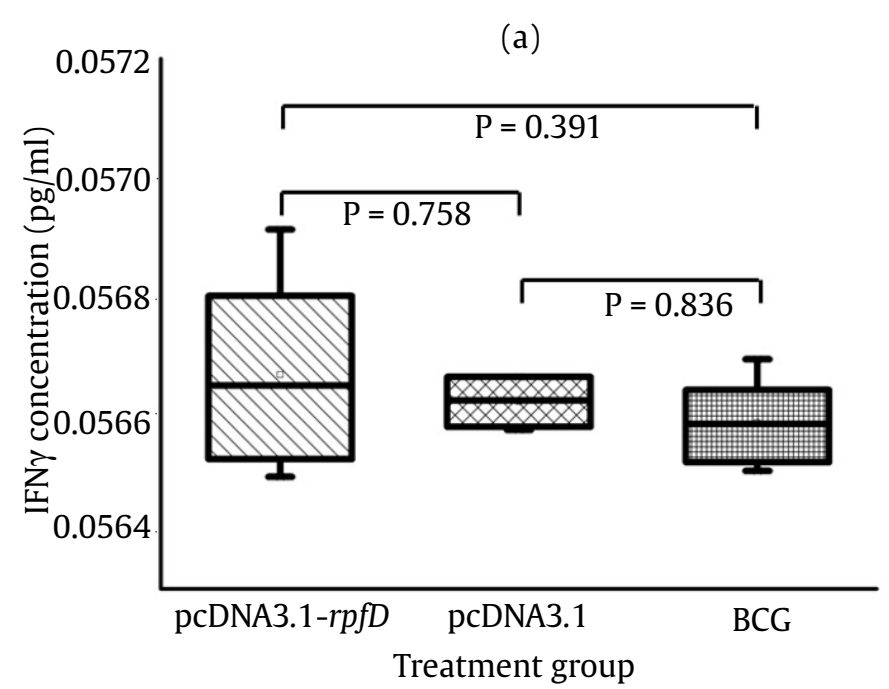

(c)

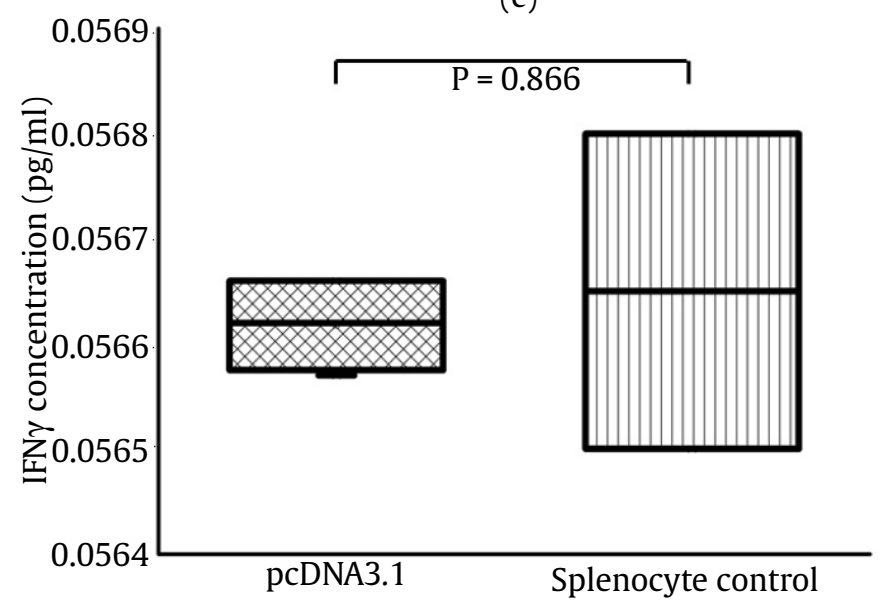

(b)

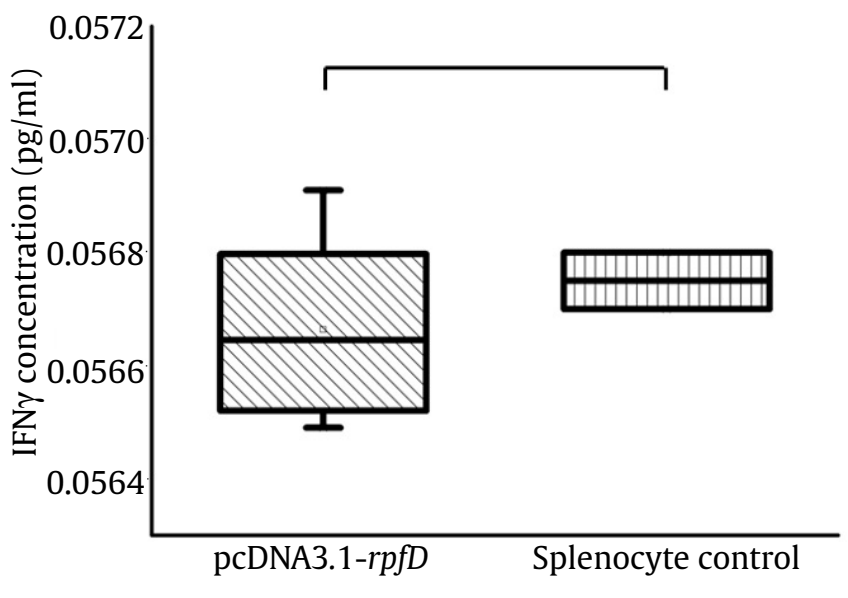

(d)

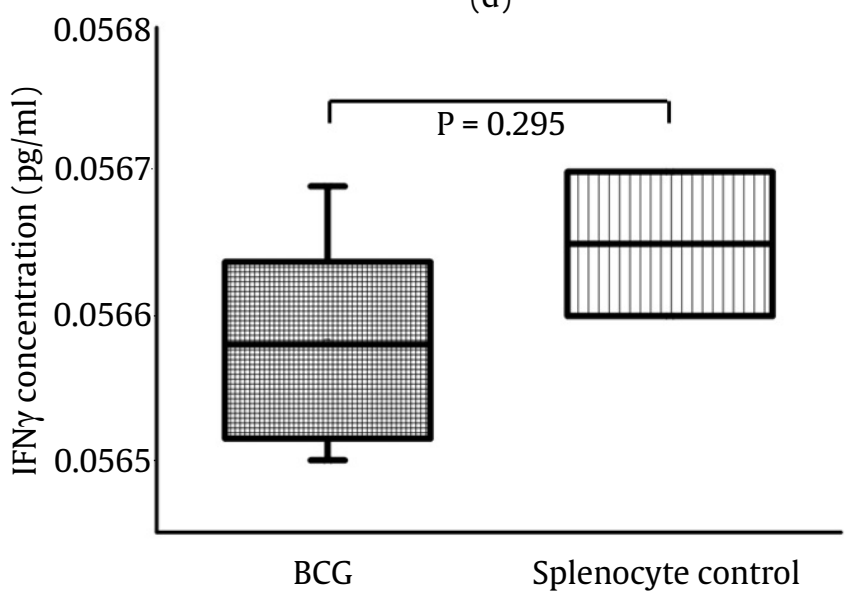

Figure 3. Comparation of IFN $\gamma$ levels from splenocytes co-culture supernatant after 96 hours incubation. (a) pcDNA3.1$r p f D$, pcDNA3.1, and BCG group have IFN $\gamma$ levels of $0.05666,0.05669$, and $0.05658 \mathrm{pg} / \mathrm{ml}$ respectively, (b) splenocytes from mice injected with pcDNA3.1-rpfD, pcDNA3.1, and BCG that cultured without M. tuberculosis has IFN $\gamma$ levels of 0.05677 , (c) 0.05668 , (d) $0.05665 \mathrm{pg} / \mathrm{ml}$ 
(a)
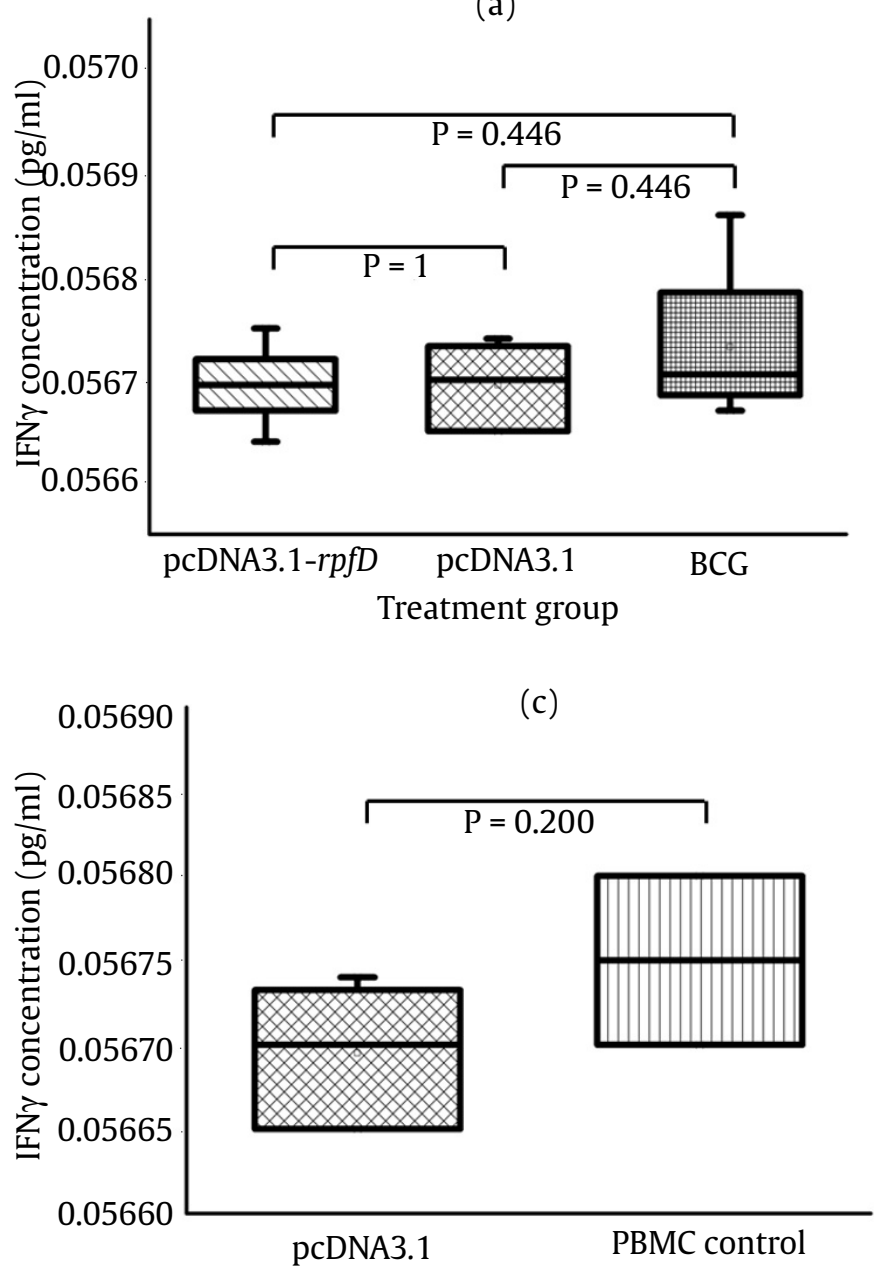
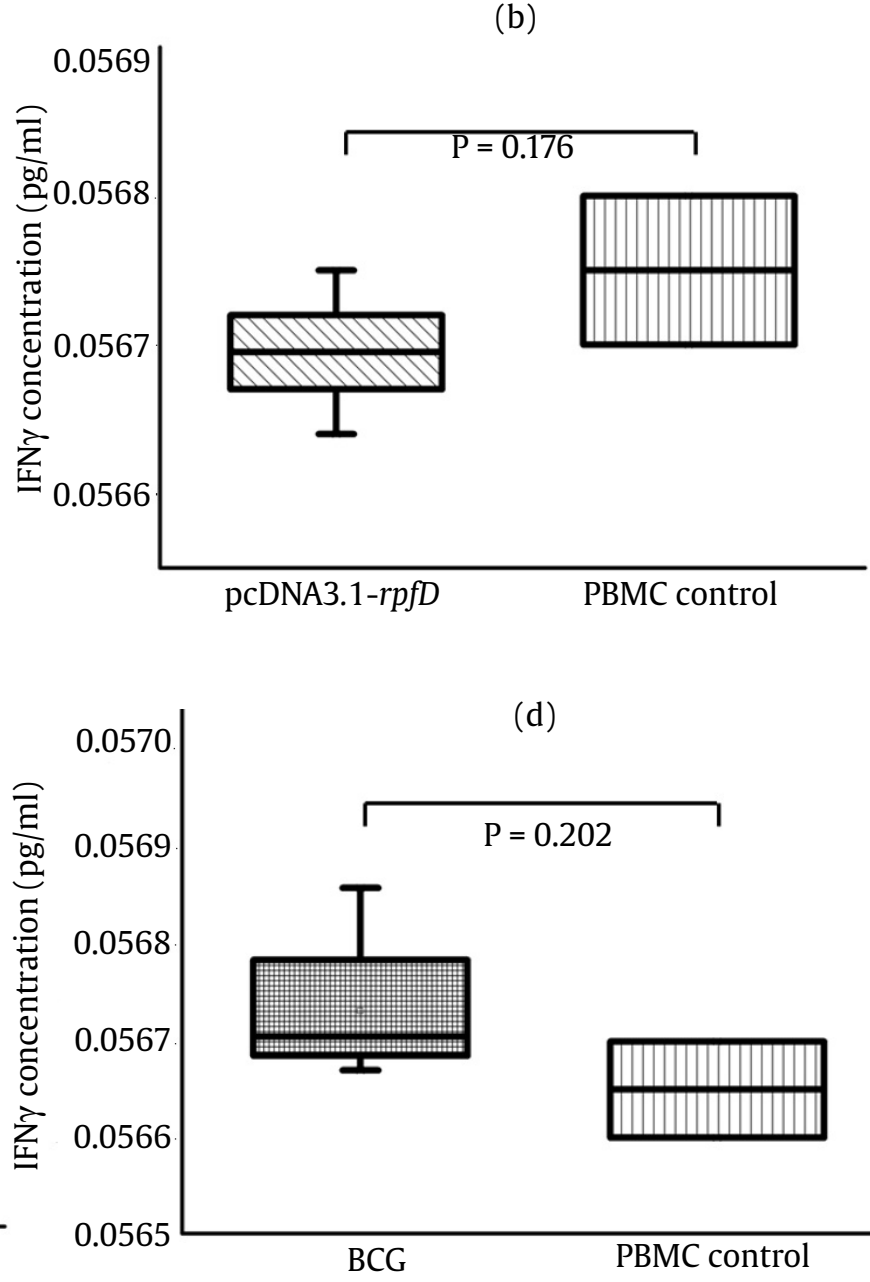

Figure 4. Comparation of IFN $\gamma$ levels from PBMC-M. tuberculosis co-culture supernatant after $96 \mathrm{~h}$ incubation. (a) pcDNA3.1-rpfD, pcDNA3.1, and BCG group have IFN $\gamma$ levels of $0.05669,0.05670$, and $0.05673 \mathrm{pg} / \mathrm{ml}$ respectively, (b) PBMC from mice injected with pcDNA3.1-rpfD, pcDNA3.1, and BCG that cultured without M. tuberculosis has IFN $\gamma$ levels of 0.0567, (c) 0.0568 , (d) $0.0567 \mathrm{pg} / \mathrm{ml}$

\subsection{Correlation of IFN $\gamma$ Levels with Time to Positivity}

The TTP value represented the ability of mammalian cells to inhibit the growth of $M$. tuberculosis in this study. The higher the TTP value, the greater the ability of mammalian cells to inhibit bacterial growth. The TTP value was then correlated with IFN $\gamma$ levels considering that this cytokine was known to play a role in the immune response against tuberculosis. Statistical analysis showed that the Pearson correlation value between IFN $\gamma$ and TTP of PBMC co-culture was -0.008 . Meanwhile, the Pearson correlation value between IFN $\gamma$ and TTP from splenocyte co-culture was 0.073 .

\section{Discussion}

In this study, MGIA was conducted using vaccinated mice's PBMCs or splenocytes co-cultured with $M$. tuberculosis. This procedure was carried out on a 48-well plate, which was more favored than culturing in a rotating tube as it increased mammalian cell viability and cytokine production (Jensen et al. 2017; Tanner et al. 2019). The number of cells used in this study was $0.0005 \mathrm{McF}$ and $3 \times 10^{6}$ for mycobacteria and mammalian cells, respectively. Regarding the number of mycobacteria, it was determined that the inhibition effect of mammalian 
cells toward mycobacteria was still observable along with the research time-wise. Besides, the number of mycobacteria of $0.0005 \mathrm{McF}$ was known to have ten days of TTP (data not shown); Zelmer et al. 2016 described that the effect of the immune response against mycobacteria was expected to be seen. As for mammalian cells, despite the more mammalian cells, the greater the effect of the immune response was, increasing mammalian cells was undesirable. It was reported that mammalian cells exceeding $5 \times 10^{6}$ could cause an event called yellowing culture media in 96 hours, leading to unhealthy mammalian cells (Painter et al. 2020).

The addition of autologous serum to the co-culture of the PBMCs ensures the effect of vaccination against M. tuberculosis. The addition of serum has been shown to enhance the effect of the immune response on bacterial growth in human PBMC cultures (Tanner et al. 2021). Meanwhile, a study by Pratama 2019 showed that pcDNA3.1-rpfD was proven to induce IgG2a anti-RpfD antibodies in the serum of BALB/C mice. The IgG2a subclass is known to play a role in the immune response through ADCC (Kips et al. 1985) and the complement system (Macedo et al. 2011). After the co-culture period was completed, all cells were centrifuged, followed by a re-culture process without lysis of mammalian cells because the lysis process, with water, PBS-Tween, saponins, SDS, or without lysis did not affect the re-culture results (Tanner et al. 2019).

The output of MGIA is the ability to inhibit the growth of $M$. tuberculosis, which can be expressed in TTP. The use of the BACTEC ${ }^{\mathrm{TM}}$ MGIT $^{\mathrm{TM}}$ system has the advantage of detecting bacterial growth faster and providing more accurate growth measurement results (Pfyffer et al. 1997; Brennan et al. 2017). Although co-culture observations with a microscope at 400x magnification did not show any morphological differences (data not shown), statistical analysis of TTP values in splenocyte and PBMC cultures showed significant differences between the treatment groups (Figure 2). These results indicate that PBMC cells from mice immunized with pcDNA3.1-rpfD or with BCG could inhibit the growth of tuberculosis. Control of mammalian cells constituting PBMCs and splenocytes without $M$. tuberculosis cells was also carried out. The TTP measurement of control mammalian cells was negative for the use of oxygen in the MGIT tube within 42 days (data not shown). These results indicated that the positive growth results in the MGIT tube, by decreasing oxygen levels in the tube, are indeed due to the growth of $M$. tuberculosis and not due to the presence of mammalian cells. These results also confirm the research by Tanner et al. 2019 that BACTEC MGITbased MGIA can be performed without mammalian cell lysis.

Indeed, the PBMC and spleen are composed of immune cells that have a role in inhibiting the growth of M. tuberculosis. Dendritic cells (DCs) that respond to the RpfD antigen from the injection site may migrate to the spleen or lymph nodes. The expression of RpfD protein has been demonstrated by Rakhmawati 2017 that anti-RpfD antibodies were detected in the serum of mice injected with pcDNA3.1-rpfD. These DCs are thought to present antigen to CD8+ T cells followed by differentiation into effector cells and finally leaving the spleen (Bronte and Pittet 2013). Effector T cells can be taken up and participate in inhibiting bacterial growth during the co-culture period. In addition, $T$ cells can differentiate into memory cells (Abbas et al. 2018). When induced with $M$. tuberculosis during coculture, these $\mathrm{T}$ cells can respond to the presence of bacteria.

Growth inhibition of $M$. tuberculosis also occurs with monocyte response. Antigens released by transfected cells may be captured by APCs, processed via the endocytosis system, and then presented to CD4+ T (Gurunathan et al. 2000; Klutzer and Weiner 2008; Li and Petrovsky 2016). These CD4+ T cells can differentiate into Th1 in the presence of the IL12 cytokine (Abbas et al. 2018). Regarding IL-12, it was determined that immunization with pcDNA3.1$r p f D$ triggered higher levels of IL-12 compared to the control group (Rakhmawati 2017). Furthermore, Th1 cells produce IFN $\gamma$, which plays a role in macrophage activation (Abbas et al. 2018). The growth of $M$. tuberculosis in co-culture was prevented in the test group, pcDNA3.1-rpfD, assuming that activated macrophages were taken up and participated in inactivity during the co-culture period.

Considering the importance of IFN $\gamma$ in eradicating M. tuberculosis, in this study, IFN $\gamma$ levels were measured using ELISA. The results showed that IFN $\gamma$ was detected in each treatment group. However, IFN $\gamma$ levels were not significantly different between the immunized group and the negative control group. These results may arise due to injection treatment in the negative control group with pcDNA3.1. This plasmid does not express the RpfD protein, but 
possible that it can express other proteins such as the neomycin resistance gene, which is part of the pcDNA3.1 plasmid (Invitrogen 2010). Neomycin resistance gene expression might triggered the production of IFN $\gamma$. Thus, in the negative control, IFN $\gamma$ was also detected by ELISA even though the production of IFN $\gamma$ was triggered by a different cause. Furthermore, statistical differences could not be detected when comparing IFN $\gamma$ levels between the pcDNA3.1-rpfD and the negative control groups. This limitation can be avoided by adding a naive BALB/c mouse not given injection treatment in subsequent studies. This naive control group can be used as a reference to normalize the data (Yang et al. 2016). On the other hand, the measurement time may have contributed to the absence of differences in levels of IFN $\gamma$. In this study, the measurement of IFN $\gamma$ levels was carried out on the $4^{\text {th }}$ day. It is possible that at that time, the levels of IFN $\gamma$ in culture are no longer sensitive to make a difference at that point. The MGIA study that found differences in IFN $\gamma$ levels was carried out by Marsay et al. 2013 by measuring the level of IFN $\gamma$ gene expression at 12 hours.

In this study, it was found that there was no relationship between IFN $\gamma$ levels and the ability to inhibit the growth of M. tuberculosis, as indicated by Pearson correlation analysis. In line with previous reports by Hoft et al. 2002; Kampmann et al. 2004; Fletcher et al. 2013; Joosten et al. 2018; Tanner et al. 2019. This phenomenon is due to the complexity of the immune response to $M$. tuberculosis, which involves various cytokines likes IL-12, IL-18, IL-23, and TNF $\alpha$, which were not measured in this study. In addition, the killing of $M$. tuberculosis itself is carried out by effector cells such as macrophages, CD4+ T cells, and CD8+ T cells, not by cytokines (Crevel et al. 2002; Schaaf and Zumla 2009). Therefore, in addition to IFN $\gamma$, it is preferred to measure the number or ratio of effector cells in co-culture (Silver et al. 1998). These findings suggest that complex immune mechanisms exerted by other cytokines and their interactions with immune cells may be responsible for the inhibition. Therefore, the MGIA results can be used as a complete method to assess vaccine potency to accompany cellular response analysis.

In conclusion, this study provides evidence that pcDNA3.1-rpfD conferred protection against $M$. tuberculosis as reflected by longer TTP compared to the negative control. As this vaccine candidate yielding greater potential, it may be feasible to proceed to the in vivo challenge assay with animal models. Moreover, the result was supported by the positive control group, BCG which has already known as an agent in preventing tuberculosis infection. Even though IFN $\gamma$ levels did not show any correlation with TTP, this finding was in line with previous evidence. Suggesting that MGIA may serve as an additional method for evaluating vaccine candidates.

\section{Acknowledgements}

This research was supported by funding from HIBAH PUTI 2020 contract number NKB-2222/UN2. RST/HKP05.00/2020 and addendum number NKB 4717/UN2.RST/HKP. 05.00/2020. The authors are grateful to Ratih Pujilestari for her assistance during the project.

\section{References}

Abbas, A.K., Lichtman, A.H., Pillai, S., 2018. Cellular and Molecular Immunology vol 9. Elsevier: Philadelphia. Brennan, M.J., Tanner, R., Morris, S., Scriba, T.J., Achkar, J.M., Zelmer, A.Z., Hokey, D.A., Izzo, A., Sharpe, S., Williams, A., Penn-Nicholson, A., Erasmus, M., Stylianou, E., Hoft, D.F., McShane, H., Fletcherf, H.A., 2017. The crossspecies mycobacterial growth inhibition assay (MGIA) project, 2010 -2014. Clinical and Vaccine Immunology. 24, 1-13. https://doi.org/10.1128/CVI.00142-17

Bronte. V., Pittet. M.J., 2013. The spleen in local and systemic regulation of immunity. Immunity. 39, 806-818. https://doi.org/10.1016/j.immuni.2013.10.010

Crevel, R.V., Ottenhoff, T.H.M., Meer, J.W.M.V.D., 2002. Innate immunity to Mycobacterium tuberculosis. Clinical Microbiology Reviews. 15, 294-309. https:// doi.org/10.1128/CMR.15.2.294-309.2002

Fine, P.E., 1995. Variation in protection by BCG: implications of and for heterologous immunity. The Lancet. 346 , 1339-1345. https://doi.org/10.1016/S01406736(95)92348-9

Fletcher, H.A., Tanner, R., Wallis, R.S., Meyer, J., Manjaly, Z.R., Harris, S., Satti, I., Silver, R.F., Hoft, D., Kampmann, B., Walker, K.B., Dockrell, H.M., Fruth, U., Barker, L., Brennan, M.J., McShane, H., 2013. Inhibition of mycobacterial mrowth in vitro following primary but not secondary vaccination with Mycobacterium bovis BCG. Clin. Vaccine. Immunol. 20, 1683-1689. https:// doi.org/10.1128/CVI.00427-13

Gurunathan, S., Klinman, D.M., Seder, R.A., 2000. DNA vaccines: immunology, application, and optimization. Annual review of immunology. 18, 927-974. https://doi. org/10.1146/annurev.immunol.18.1.927

Hoft, D.F., Worku, S., Kampmann, B., Whalen, C.C., Ellner, J.J., Hirsch, C.S., Brown, R.B., Larkin, R., Li Yun, H., Silver., 2002. Investigation of the relationships between immune-mediated inhibition of mycobacterial growth and other potential surrogate markers of protective Mycobacterium tuberculosis immunity. Journal of Infectious Disease. 186, 1448-1457. https:/| doi.org/10.1086/344359

Invitrogen. 2010. pcDNA3.1(+)pcDNA3.1(-). Invitrogen: USA.

Jensen $C$ et al. 2017. Optimisation of a murine splenocyte mycobacterial growth inhibition assay using virulent Mycobacterium tuberculosis. Scientific Reports. 7, 1-13. https://doi.org/10.1038/s41598-017-02116-1 
Joosten, S.A., Lindebo Holm, L., Svensson, E., Aagaard, C, Ruhwald, M., 2018. Mycobacterial growth inhibition is associated with trained innate immunity. Journal of Clinical Investigation. 128, 1837-1851. https://doi. org/10.1172/JCI97508

Kampmann, B., Tena, G.N., Mzazi, S., Eley, B., Young, D.B., Levin, M., 2004. Novel human in vitro system for evaluating antimycobacterial vaccines. Infection and Immunity. 72, 6401-6407. https://doi.org/10.1128/ IAI.72.11.6401-6407.2004

Kipps, T.J., Parham, P., Punt, J., Herzenberg, L.A., 1985. Importance of immunoglobulin isotype in human antibody-dependent, cell-mediated cytotoxicity directed by murine monoclonal antibodies. Journal of Experimental Medicine. 161, 1-17. https://doi. org/10.1084/jem.161.1.1

Kutzler, M.A., Weiner, D.B., 2008. DNA vaccines: ready for prime time? Nature reviews. Genetics. 9, 776-88. https://doi.org/10.1038/nrg2432

Li, L., Petrovsky, N., 2016. Molecular mechanisms for enhanced DNA vaccine immunogenicity. Expert review of vaccines. 15, 313-329. https://doi.org/10.1 586/14760584.2016.1124762

Macedo, G.C., Bozzi, A., Weinreich, H.R., Bafica, A., Teixeira, H.C., Oliveira, S.C., 2011. Human T cell and antibodymediated responses to the Mycobacterium tuberculosis recombinant $85 \mathrm{~A}, 85 \mathrm{~B}$, and ESAT-6 antigens. Clinical and Developmental Immunology. 2011, 1-10. https:// doi.org/10.1155/2011/351573

Marsay, L., Matsumiya, M., Tanner, R., Poyntz, H., Griffiths, K.L., Stylianou, E., Marsh, P.D., Williams, A., Sharpe, S., Fletcher, H., McShane. H., 2013. Mycobacterial growth inhibition in murine splenocytes as a surrogate for protection against Mycobacterium tuberculosis (M.tb). Tuberculosis. 93, 551-557. https://doi.org/10.1016/j. tube.2013.04.007

Mukamolova, G.V., Turapov, O.A., Young, D.I., Petrovskaya, S.N., Kazarian, K.A., Telkov, M.V., 2002. A family of autocrine growth factors in Mycobacterium tuberculosis. Molecular Microbiology. 46, 623-635. https://doi.org/10.1046/j.1365-2958.2002.03184.x

Ordway, D.J., Orme, I.M., 2001. Animal models of mycobacteria infection. Current Protocols in Immunology. 94, 1-54. https://doi.org/10.1002/0471142735.im1905s94

Painter, H., Prabowo, S.A., Cia, F., Stockdale, L., Tanner, R., Willcocks, S., Reljic, R., Fletcher, H.A., Zelmer, A., 2020. Adaption of the ex vivo mycobacterial growth inhibition assay for use with murine lung cells. Scientific Reports. 10, 1-9. https://doi.org/10.1038/ s41598-020-60223-y

Pfyffer, G.E., Welscher, H.M., Kissling, P., Cieslak, C., Casal, M.J., Gutierrez, J., Rusch-Gerdes, S., 1997. Comparison of the mycobacteria growth indicator tube (MGIT) with radiometric and solid culture for recovery of acid-fast bacilli. Journal of Clinical Microbiology. 35, 364-368. https://doi.org/10.1128/jcm.35.2.364-368.1997

Pratama, W.A., 2019. Profil Subkelas IgG Mencit yang Diimunisasi dengan Kandidat Vaksin DNA Tuberkulosis yang Mengekspresikan Resuscitation Promoting Factor-D [Thesis]. Jakarta, Indonesia: Universitas Indonesia.
Rakhmawati, A., 2017. Pengembangan Seed Vaksin Tuberkulosis: Konstruksi Vaksin DNA Resuscitation Promoting Factor D ( $r p f D$ ) serta Analisis Respon Imun Humoral dan Seluler pada Mencit Balb/c [Thesis]. Jakarta, Indonesia: Universitas Indonesia.

Riedhammer, C., Halbritter, D., Weissert, R., 2014. Peripheral blood mononuclear cells: isolation, freezing, thawing, and culture. Methods in Molecular Biology. 1304, 53-61. https://doi.org/10.1007/7651_2014_99

Schaaf, H.S., Zumla, A., 2009. Tuberculosis: A Comprehensive Clinical Reference. Saunders Elsevier Inc: Philadelphia.

Silver, R.F., Li, Q., Boom, W.H., Ellner, J.J., 1998. Lymphocytedependent inhibition of growth of virulent Mycobacterium tuberculosis H37Rv within human monocytes: requirement for CD4 + T cells in purified protein derivative-positive, but not in purified protein derivative-negative subjects. The Journal of Immunology. 160, 2408-2417.

Tanner, R.L., 2015. Development of Mycobacterial Growth Inhibition Assays for the Early Evaluation and Gating of Novel TB Vaccine Candidates [Dissertation]. England: University of Oxford.

Tanner, R., Smithb, S.G., van Meijgaardenc, K.E., Giannonid, F., Wilkiea, M., Gabrielee, L., Palma, C., Dockrell, H.M., Ottenhoff, T.H.M., McShane, H., 2019. Optimisation, harmonisation and standardisation of the direct mycobacterial growth inhibition assay using cryopreserved human peripheral blood mononuclear cells. Journal of Immunological Methods. 469, 1-10. https://doi.org/10.1016/j.jim.2019.01.006

Tanner, R., Hoogkamer, E., Bitencourt, J., White, A., Boot, C., Sombroek, C.C., Harris, S.A., O'Shea, M.K., Wright, D., Wittenberg, R., Sarfas, C., Satti, I., Verreck, F.A.W., Sharpe, S.A., Fletcher, H.A., McShane, H., 2021. The in vitro direct mycobacterial growth inhibition assay (MGIA) for the early evaluation of TB vaccine candidates and assessment of protective immunity: a protocol for nonhuman primate cells. F1000Research. 10, 1-23. https://doi.org/10.12688/ f1000research.51640.2

[WHO] World Health Organization. 2020. Global Tuberculosis Report. France: World Health Organization.

Yang, A.L., Schmidt, T.E., Stibitz, S., Derrick, S.D., Morris, S.L. Parra, M., A 2016. Simplified mycobacterial growth inhibition assay (MGIA) using direct infection of mouse splenocytes and the MGIT system. Journal of Microbiological Methods. 131, 7-9. https://doi. org/10.1016/j.mimet.2016.09.010

Zelmer, A., Tanner, R., Stylianou, E., Damelang, T., Morris, S., Izzo, A., Williams, A., Sharpe, S., Pepponi, I., Walker, B., Hokey, D.A., McShane, H., Brennan, M., Fletcher, H., 2016. A new tool for tuberculosis vaccine screening: ex vivo mycobacterial growth inhibition assay indicates BCG-mediated protection in a murine model of tuberculosis. BMC Infectious Diseases 412:19. https://doi.org/10.1186/s12879-016-1751-4 